\title{
The modal nature of ICT: Challenging historical interpretation of the social understanding and appropriation of ICT
}

\author{
Marcus Leaning \\ Trinity College $<\underline{\text { m.leaning@trinity-cm.ac.uk }}>$
}

\begin{abstract}
This paper proposes a sociological model for understanding the social appropriation of information and communications technology (ICT). It is argued that the relationship between a media form and the society in which it is deployed is of key import in understanding how media is used. An account is given of the way in which the power of ICT to affect society has been understood. It is argued that positions within this debate are deeply tied to Western cultural beliefs and values. An alternate model of technology is proposed. In this model ICT is regarded as 'modal' in operation, that is, it may operate differently in different situations.
\end{abstract}

\section{Introduction}

Information and communication technologies (ICTs) have been widely understood to bring about social change. For example, ICTs have been thought to: invigorate economic systems (Gates, 2000), empower citizens (Gore, 1994) and even contribute to social and psychological well-being (Cole, et al., 2001). This article advocates a slightly different position; that the ability of a media or technology, such as ICT, to bring about change is tied very much to the social form of the society in which it is deployed. The manner in which a technology is used, its "local" appropriation, is argued to be more closely linked to the social organisation of the society in which the technology is deployed than any essential qualities the technology itself is understood to possess. This argument was, of course, initially set forth by Raymond Williams (1974). Moreover, it has received a partial re-articulation by a number of academics in recent years, (Slevin, 2000; Miller \& Slater, 2000; Selwyn \& Gorrard, 2002) but has seemingly lost out to the neoMcLuhanite approaches advocated by numerous techno-optimists (Bolter, 2002). The emergence of Community Informatics as an academic discipline presents an opportunity to re-engage with the social side of ICT. Indeed as Selwyn and Gorrard contend "there is clearly a pressing need to step beyond the limitations of previous analyses of ICT if we are to gain a deeper understanding... We need to be aware of the social, cultural, political, economic and technological aspects of ICT-the 'soft' as well as the 'hard' concerns" (p. 6). As Harris (2002) and Taylor (2004) both indicate, Social Informatics is a discipline that requires focus to be placed not upon the rarefied use of ICT but upon their use in social situations. In such situations, the "dominant referent discipline" (as Harris suggests), moves from economics and marketing to social science. This shift to a social scientific, if not a sociological, critical idiom incorporates an implicit re-emphasis upon social factors in the understanding of the use of ICT.

Much early literature on the subject of the social use of ICT incorporated a sense of "technological utopianism". ICT was understood as a means by which desirable values, understood to have been lost in recent times, could be restored. Rheingold (1993), for example, utilising an instrumentalist conception of technology usage, proposed, "one of the explanations for the virtual community phenomenon is the hunger for community that grows in the breasts of people around the world as more and more informal public 
spaces disappear from our real lives" (p. 6). Similarly Schuler (1996), with a more technological determinist approach, contended that virtual communities "can-in concert with other efforts-play a positive role in rebuilding community by strengthening.... core values" (p. 34). The emphasis here has been very much along liberal progressive lines and perhaps narrow conceptualisations of communities, core values and "positive" roles.

Such opinions can be seen as examples of a belief in the power of ICT to provide a "technological fix" (Selwyn \& Gorrard, 2002) - the ability of technology to solve complex social problems. Leaning (2004) argues that such an interpretation of ICT arises as ICT has primarily been studied in societies in where such beliefs are the common currency. ICT is imbued with a potency to restore liberal values as it has primarily been studied in societies where such values are desirable and perceived as being threatened. This argument resonates strongly with the views of Downing (1996), who argues for the study of ICT (along with other media forms) outside of the traditional laboratories of Western Europe, North America and Oceana.

This article continues this line of argument. It is asserted that ICT's potency to cause change is closely tied to the society in which it is deployed and, furthermore, attention should be placed upon both the technology and the society equally. As Miller and Slater (2000, p. 11) argue, "if you want to get to the Internet, don't start from there".

However, the relationship of ICT to social form has as yet to be fully explored. This article is concerned with sketching a sociological model by which the relationship of ICTs to society may be understood. This proposal consists of two arguments. The first is that current understandings of the way in which technology is used, appropriated and affects society derive from the experience of technological development and the philosophic interpretation of this experience in Western societies. In many instances it is the West's experience of technology that has shaped and informed the general cultural interpretation of how technology can and should be deployed and used. Regarding the West's experience as universal is problematic for, as Hård and Jamison (1998) propose, cultural tradition plays a considerable part in conceptions of technology and technological power. What is required is recognition that current interpretations of the power of ICT are deeply and historically situated within a Western cultural milieu. The intricacies of this interpretation need to be foregrounded and examined.

Secondly, an alternate model of how technology may operate in relation to society is needed. While the current model of ICT power is intricately bound up with a Western interpretation, it must be acknowledged that technology and social form do exist in a close relationship. What is needed, therefore, is a model of technology that does not "close off" non-Western cultural interpretations of technology. This model regards technology not as in some way an external force affecting society, but as a phenomenon constructed, appropriated and understood by society. The model conceptualises technology not as a fixed external, eternal aspect of the social world but instead as a part of the social world. Accordingly, ICT should be regarded as something operating and existing in a plurality of forms. Technology needs to be understood as something that may interact with society in various ways. It is proposed here that ICT be understood as being "modal" - something that may be used in a particular way in one society but in a different way in another. Technology possesses no quality that necessitates its particular form of use or societal level consequence.

\section{The Understanding of ICT's Relationship to Society}

Underpinning discussions of technology, such as contemporary discourse surrounding ICTs, are deeply felt, but often unarticulated, assumptions of how technology and people interact. The relationship between technology and society, particularly in discussions concerning new technologies, is often assumed to be of a simple deterministic nature; the introduction of new technology causes social change. However there are slight, historically situated, variations to this model. In proposing a philosophical-anthropological orientation to the study of technology, Feenberg (1999) contends that within modern discourse the relationship of technology with society has been conceived of in a number of different ways. Using a broadly Kuhnian (Kuhn, 1962) approach, Feenberg argues that discourses of technological understanding, like scientific paradigms, emerge from "local" historical conceptions, and are interwoven with political and social projects. He asserts that the development of such an analysis is key to grasping a sense of 
technology's significance, asking "How can one study specific technologies without a theory of the larger society in which they develop?" (Feenberg, 2003). The categories Feenberg identifies, instrumentalism, determinism and substantivism, thus may offer a richer and more detailed account of the beliefs underpinning accounts of technology, and consequently ICT.

\section{Instrumentalism}

Feenberg states that the classical disciplines of the humanities exclude science and technology. It is only since the emergence of the discourses of modernity that accounts of technology have become more central. However, as Winner (1987) notes, such views of technology were largely instrumental, as technology was often subsumed under the rubric of "economics" or "politics". This account of technology persists today, for, as Winner $(1987$, p. 2) states, there is still an open "tendency ... to see the matter solely in terms of economics and economic history". In addition to the relegation of technology to a position subordinate to economics or politics, instrumental accounts of technology tend to centre on certain unchallenged assumptions. Winner (pp. 25-27) states that: "In the conventional perspective... technical means are by their nature mere tools subject to the will of whomever employs them.... Technology is essentially neutral. In the conventional way of thinking, the moral context appropriate to technical matters is clear. Technology is nothing more than a tool."

The instrumental understanding of technology holds that technology is "essentially neutral" and subservient. The idea of the neutrality of technology presupposes an established position of objective truth, one that has been discerned through scientific investigation. According to this idea, technological artefacts are different from cultural artefacts in that they are purely means-oriented, a position arising out of a view of technology as essentially progressive. Furthermore, in instrumental thought, as Feenberg (2003, p. 3) notes, technology "appears as purely instrumental, as value-free. It does not respond to inherent purposes, but is merely a means of serving subjective goals we choose as we wish". Instrumentalist readings of technology still circulate widely within the more scientific disciplines and have proven quite influential in more positivist approaches to the study of communication (see for example Weaver and Shannon, 1963).

\section{Determinism}

Along with the instrumental reading of technology, a second and persistent understanding of technology is evident within the discourses of modernity. Broadly referred to as determinist, this category has as its mainstay a belief in the potential of technology to bring about social change on a macro or societal level. Technological determinism has proven a strong and persistent strand of thought in understanding the role of technology within modern Western thought even though it seems rarely to be explicitly stated. Marx and Smith (1996, pp. ix-xv) contend: “A sense of technology's power as a crucial agent of change has a prominent place in the culture of modernity. It belongs to the body of widely shared tacit knowledge that is more likely to be acquired by direct experience than by the transmittal of explicit ideas".

Similarly, Bimber proposes: "Technological determinism seems to lurk in the shadows of many explanations of the role of technology" (1996, p. 80). With regards to a general description of technological determinism, Heilbroner summarises the argument as follows: "Machines make history by changing the material conditions of human existence. It is largely machines... that define what it is to live in a certain epoch" (1996, p. 69). Feenberg contends that such a trend emerged out of notions of progressivism within the Enlightenment and, more specifically, an engagement with the progressivism of Marx and even Darwin (2003, pp. 1-2). In post-Enlightenment European society, progress came to be broadly equated with an acknowledgement of technology's power; "progressivism had become technological determinism" (Feenberg, pp. 1-2).

This form of understanding has proven highly persistent and popular. It continues to manifest itself in numerous formats. For example, one particular and contemporary understanding equates the deployment of technology with improved social conditions. A number of populist accounts, for example Kawamoto (2003), regard the deployment of ICT as a necessary precursor to the development of a "knowledge economy" or "information society". Several national governments have sought a rapid deployment of 
technology in pursuit of economic and social development. For example, in a statement by the Welsh Assembly detailing its Information and Communication Strategy it is contended that: "Many of us are now using computers, mobile phones and the Internet...These technologies have the potential to transform society and the economy in Wales; they are already doing so in many parts of the world. The choices we make now - about which new technologies we use and, more importantly, how we use them-are crucial to the future of Wales and will help us to create a Better Wales!" (Welsh Assembly Government, 2003).

Similarly, the Malaysian government has instigated, and to a degree acted upon, plans to "leapfrog into the Information Age", developing a "Multimedia Super-Corridor", a region of technological development incorporating purpose-built cities and a university all underpinned by highly developed technological infrastructure (Multimedia Development Corporation, 2000).

\section{Substantivism}

A range of attitudes broadly termed substantivist challenge the determinist belief in the neutrality and truth-revealing nature of technology (Feenberg, 2003, p. 2). As instrumentalism and determinism are understood to have emerged from empiricist and positivist tendencies within Enlightenment thought, substantivism is understood to have arisen from the distrust of technology and the reassertion of the "natural" found within Romanticist discourse. Similar to determinist discourse, substantivists contend that technology can directly intersect with and modify social life. However, substantivism avoids the utopian and optimistic tendencies that characterise determinist accounts and instead maintains deep reservations about technology. Technology is understood to, inherently, subjugate the user to systems not initially declared in the operation of the technology. Such a belief reaches its most eloquent form in Heidegger's The Question Concerning Technology (1954). Heidegger proposes that technology is far from the neutral or simply goal-oriented system determinists or instrumentalists would claim. Rather: "we are delivered over to it in the worst possible way when we regard it as something neutral; for this conception of it, to which today we particularly like to do homage, makes us utterly blind to the essence of technology" (p. 4).

Technology contains an "essence": Heidegger envisages that technology is not about achieving goals but about revealing or bringing forth the use of a resource. However, "modern technology is fundamentally different from what Heidegger regards as ancient technology. The form of revealing is primarily different because of the physics-based nature of modern technology that allows for the ordering of a "standing reserve" at the behest of humans. This is opposed to the fundamental primacy of natural forces in old technology. However, Heidegger regards modern technology as inherently insidious, as humans do not control this; humans form part of the system of standing reserve. Humans are "enframed" by technology and technological systems and lose their freedom through their incorporation into technological systems. While Heidegger offers a radical reading of technology it lacks a sociologically "critical" aspect in that "fault" is understood to lie with modern technology as an entity as opposed to the more critical conflicts and power relations that underpin modernity.

Substantivist thought also incorporates a spectrum of opinion that links the subjectifying nature of technology with specific political projects - a radicalising and politicising of Romantic thought. Technology is conceptualised as inherently political, Winner contends: "At issue is the claim that machines, structures, and systems of modern material culture can be accurately judged not only for their contributions of efficiency and productivity, not merely for their positive and negative side effects, but also for the ways in which they can embody specific forms of power and authority" (1996, p. 28).

At the core of such claims lies a different conceptualisation of the nature and understanding of the origin of technological artefacts to that of the instrumentalists and the determinists. Here, in an engagement with Kuhnian theory, substantivism explicitly challenges the notion that technology is a truth-revealing (or revealed) phenomenon; on the contrary, technology arises from, and is broadly shaped by, society. Substantivists argue that technology cannot be distinctly discerned from other forms of cultural production and, as with all forms of cultural production, technology is inherently stained by the situation of its material and economic production.

Substantivism offers a theory not only of the effects of technology upon society, but also of the effects of society upon technology. Qvortrup opines that new technology "cannot be properly understood if we persist in treating technology and society as two independent entities" $(1984$, p. 7$)$. Technology needs to be 
understood as a component of society. Consequently, and most importantly, technology is in essence determined by the society in which it originates. It is an artefact of a civilisation and not "a progressive quest towards truth". Technology is not the neutral artefact presumed by instrumentalists and determinists. For a substantivist, technology is inherently compromised by its site of production. As Marcuse proposes: "Specific purposes and interests of domination are not foisted upon technology 'subsequently' and from the outside; they enter the very construction of the technical apparatus. Technology is always a historical-social project: in it is projected what a society and its ruling interests intend to do with men and things. Such a 'purpose' of domination is 'substantive' and to this extent belongs to the very form of technical reason" (italics in original, 1968, p. 224).

It is in this critical and dystopian dimension, where technology contains the insidious "will" of its situation of manufacture, and where substantivist accounts are distinguished from the utopian progressive accounts of technology proffered by determinists. Technology is inherently a problematic system of control for substantivists, a form of instantiated power. Contrasted with the instrumental and determinist interpretations of technology, substantivism offers a highly pessimistic and critical reading of the further integration of social functions within systems of technology.

The above-noted multiple forms of understanding of technology's interaction with society constitute the general range of opinion on the topic. While the range of views examined is not exhaustive of the entire body of thought within the field, the beliefs and opinions cited can be considered to be representative of the general prevailing ideas in circulation and they can be seen to set out the parameters of the debate.

\section{The Alternate Model: ICT as Modal}

In examining the deep cultural and historical origin of the arguments surrounding technology, the very nature of the way in which technology, and consequently ICTs, are conceptualised is questioned. As technology may be interpreted in differing ways, a conceptual model of technology and ICT that allows for multiple interpretations is needed.

In light of this, it is proposed that ICTs be regarded as contingent or modal forms of communication. It should be noted that this use of the terms "mode", "modal" and "modality" is distinct from a number of other uses of the terms in media and communications theory. Rather than arguing that ICTs are a mode or form of communication or cultural transmission-it is proposed that the ICTs have modal quality in relation to their use, that they have different modes of use. As with Thompson (1990, pp. 216-264), it is argued that media, such as ICTs, are socially contingent means of communicating information and, following Kress and Van Leeuwen (2001), that the Internet itself is a mode of communication, or as Slevin (2000) proposes, that it is to be seen as a modality of cultural transmission.

Therefore, the use of the term here is different. Modal refers to the multiple ways in which ICTs may be read, understood and used. Although ICTs may function in certain ways in some societies, they may not function in that way in all societies. ICTs may cause change and, as has been noted by numerous previous researchers, may bring about new ways of acting. However, we are contending that they may not do so in the same way in all societies, with the ability of technology to cause change being deeply linked to other aspects of social life. ICT, thus, is not understood as an asocial channel that passes information, regardless of the environment in which it is used. Instead it needs to be understood as deeply linked to the social systems and contexts in which it is used-ICT use depends upon the social environment.

It is therefore proposed that, methodologically, ICTs be conceptualised in the following way:

ICTs are a modal form of media and their use and appropriation may vary according to the environment in which they are used. Therefore, to examine ICTs, attention should be focused upon the interdependence of social systems, media technology and form of action studied.

Like all technology, ICTs are not outside of society, they are interpreted, appropriated and used within social frameworks. Consequently there can be no single interpretation of the outcome of their use- they will not have the same effect in all places and at all times. We must, therefore, understand their use as deeply linked to the society in question. 
Adopting such a position involves stepping back from the direct acceptance of our view of technology or of our interpretation of what technology can do. It challenges the idea that either technology or society should be considered as a priori in conception. The focus of attention shifts from a focus upon the implicit potency of a technology to an analysis of how a society makes use of the technology. As noted above, it affords an opportunity to develop a social account of the use of ICT, an approach that integrates the potency of ICT within a social or sociological account of action. It is argued that the discipline of Community Informatics is well suited to, and will benefit from, developing a critical idiom that can examine the technological and sociological in concert rather than as discrete and distinct elements.

\section{References}

Bimber, B. (1996). Three faces of technological determinism. In M. R. Smith \& L. Marx (Eds.), Does technology drive history? The dilemma of technological determinism (pp. 79-100). Cambridge, MA: MIT Press.

Bolter, D. (2002). Formal analysis and cultural critique in digital media theory. Convergence, 8(4), 77-88.

Cole. J., Suman, M., Schramm, P., Lunn, R., Coget, J. F., Firth, D., Fortier, D., Hanson, K., Qin, J., Singh, R., Yamauchi, Y., \& Aquino, J. S. (2001). The UCLA Internet report 2001: Surveying the digital future, Year two. Retrieved October 16, 2003, from http://www.digitalcenter.org/pdf/InternetReportYearTwo.pdf.

Downing, J. (1996). Internationalising media theory. London: Sage.

Feenberg, A. (1999). Questioning technology. London: Routledge.

Feenberg, A. (2003). What is philosophy of technology? Retrieved July 25, 2003, from http://wwwrohan.sdsu.edu/faculty/feenberg/komaba.htm

Gates, B. (2000). Business at the speed of thought: Using a digital nervous system. London: Penguin.

Gore, A. (1994). The Global Information Infrastructure: Forging a new Athenian Age of Democracy. Intermedia, 22 (2), 4-7.

Harris, R. (2002). Research partnerships to support rural communities in Malaysia with information and communication technologies. In J. Lazar (Ed.), Managing IT/community partnerships in the 21st Century (pp. 222-247). Hershey, PA: Idea Group Publishing.

Hård, M. \& Jamison, A. (1998). Conceptual framework: Technology debates as appropriation processes. In M. Hård \& A. Jamison (Eds.), The intellectual appropriation of technology: Discourses on modernity, 1900-1930 (pp. 1-15). Cambridge, MA: MIT Press.

Heidegger, M. (1954) [1977]. The question concerning technology. In W. Lovitt, The question concerning technology and other essays (pp. 3-35). New York: Harper Torchbooks.

Heilbroner, R. (1996). Technological determinism revisited. In M. R. Smith \& L. Marx (Eds.), Does technology drive history? The dilemma of technological determinism (pp. 58-78). Cambridge, MA: MIT Press..

Kawamoto. K. (2002). Media and society in the digital age. Boston, MA: Pearson.

Kress, G., \& Van Leeuwen, T. (2001). Multimodal discourse: the modes and media of contemporary communication. Oxford: Oxford University Press.

Kuhn, T, (1962). The structure of scientific revolutions. Chicago: Chicago University Press.

Leaning, M. (2004). Contributions to a sociology of the internet: A case study of the use of the internet in the Republic of Croatia in the 1990s. Unpublished doctoral dissertation, University of Luton.

Marcuse, H. (1968). Negations. (J. Shapiro, Trans.). London: Penguin Press.

Marx, L., \& Smith, M, (1996). Introduction. In M. R. Smith \& L. Marx (Eds.), Does technology drive history? The dilemma of technological determinism (pp. i-xxi). Cambridge, MA: MIT Press. 
Miller, D., \& Slater, D. (2000). The Internet: An ethnographic approach. London: Berg.

Multimedia Development Corporation. (2000). About MSC-Overview. Retrieved October 16, 2005, from http://www.msc.com.my/msc/msc.asp.

Qvortrup, L. (1984). The social significance of telematics: An essay on the information society (P. Edmonds, Trans.). Philadelphia: John Benjamins.

Rheingold, H. (1993). The virtual community: Homesteading on the electronic frontier. Reading, MA: Wesley Publishing.

Schuler, D. (1996). New community networks: Wired for change. New York: ACM Press.

Selwyn, N., \& S. Gorard. (2002). The Information age: Technology, learning and exclusion in Wales. Cardiff: University of Wales Press.

Slevin, J. (2000). The internet and society. Cambridge: Polity Press.

Taylor, W. (2004). Social appropriation of internet technology: A South African platform. The Journal of Community Informatics, 1(1), 21-29.

Thompson, J. (1990). Ideology and modern culture. Cambridge: Polity Press.

Weaver, W., \& Shannon, C. (1963). The mathematical theory of communication. Illinois: University of Illinois Press.

Welsh Assembly Government. (Undated). Online for a better Wales. Retrieved July 12, 2003, from http://www.cymruarlein.wales.gov.uk.

Williams, R. (1974). Television: Technology and cultural form. London: Routledge.

Winner, L. (1987). Autonomous technology: Technics-out-of-control as a theme in political thought. Cambridge, MA: MIT Press.

Winner, L. (1996). Do artefacts have politics? In D. MacKenzie \& J. Wacjcman (Eds.), The social shaping of technology (pp. 26-39). Buckingham: Open University Press. 